\title{
Research on the Combination Forecast Model based on the BP Neural Network
}

\author{
Shengwang Zong \\ Hebei Finance University,Baoding,071000, China
}

Keywords: Neural Network; Back Propagation; Combination Forecast; Adaptive Linear Element

\begin{abstract}
According to the combined forecasting theory and BP neural network for nonlinear data good approximation properties, is proposed based on Bayesian combination, $\mathrm{GM}(1,1)$ model and regression model of $\mathrm{BP}$ neural network combination forecast model. In this paper, the short-term number of railway passenger forecasting is used as the special case to illustrate the combined forecasting theory and BP neural network. Then to railway passenger traffic and railway mileage to between 2003 and 2011 as the basic data for prediction of railway passenger traffic from 2012 to 2016.Prediction results show that this model can objectively reflect the development trend of railway passenger traffic, can obtain more accurate prediction results, offer the decision basis for related departments.
\end{abstract}

\section{Introduction}

Because a single prediction method has been difficult to obtain satisfactory results, and a combination of predictors with high prediction accuracy has continued to be used. And a single model compared combination forecasting higher prediction accuracy, predict the results more reliable. This article will GM $(1,1)$ model, the regression model and BP neural network model organic combination, a combination of established BP neural network forecasting model, and applied for railway passenger volume forecast.

Our incomes and living standards to improve passenger railway transport made increasing demands; the railway is also facing a severe test. To promote the sound development of railway passenger traffic on the long-term prediction of railway passenger has very important significance. At present, the method for predicting the railway passenger traffic there are many methods commonly used are: linear regression, random time series method, gray system model and neural network model method. Xia Guo'en proposed railway passenger volume time series prediction method for improving SVR based on SVR method and BP artificial neural network method were compared, results showed that, SVR method can obtain more accurate predictions.

Wang Wen-li railway passenger volume presents a dynamic resolution adopted coefficient of gray relational analysis method to obtain the factors associated with the degree of passenger traffic, optimize the railway passenger volume forecast model selection factors. Hou Limin for railway passenger transport system is an information system is not completely gray, gray prediction theory to build gray model GM $(1,1)$ model with a combination of linear regression for the next five years, Henan Province, the railway passenger traffic volume forecasting. In this paper, a combination of BP neural network forecasting model to predict railway passenger volume, and the combination of predicted results were compared with a single prediction, the results show that the model predictions for the railway passenger volume is feasible and effective.

The article is structured as follows: Introduction the second part, the Section 3 is a combination forecasting model based on BP neural network for railway passenger traffic forecasting and analysis, the fourth part is the conclusion.

This paper is divided into different sections. Section 2 introduced combination forecasting model to establish. The Section 3 is a combination forecasting model based on BP neural network for railway passenger traffic forecasting and analysis. Lastly, conclusions are described in Section4. 


\section{Establishment of model}

In this section, there are three important parts. One is the approaches to establish the GM $(1,1)$ model. These are interpreted in the papers. The second one talks about the regression model. The last one is the BP model.

\section{GM $(1,1)$.}

Grey prediction theory is based on the past and the now known or non-deterministic information to establish a gray model from the past to the future, so as to determine the future development trend. Grey forecasting model is based on the generation of new sequence to establish differential equation model.GM $(1,1)$ model modeling process is as follows:

Assuming that a given primitive time sequence is:

$x^{(0)}=\left[x^{(0)}(1), \quad x^{(0)}(2), \cdots \quad x^{(0)}(n)\right]$

Generating the first-order accumulative sequence is:

$x^{(1)}=\left[x^{(1)}(1), \quad x^{(1)}(2), \quad \cdots \quad x^{(1)}(n)\right]$

Building a first order linear differential equation is:

$$
\frac{d x^{(1)}}{d t}+a x^{(1)}=b
$$

The final GM $(1,1)$ time response sequence is:

$$
\hat{x}^{(1)}(k+1)=\left(x^{(0)}(1)-\frac{b}{a}\right) e^{-a k}+\frac{b}{a}
$$

\section{Regression Model.}

Regression analysis is to identify the two or more variables quantitative relationship of interdependence between statistical analysis methods. It with the number of the correlation between the variables of contact are measured, determine a related mathematical equations. Often have a variable is the independent variable, remember to $\mathrm{x}$, and another variable is the dependent variable, remember to y. From excel can follow a linear, polynomial (second order), index type of close to the trend of the data line and the corresponding regression equation and correlation coefficient, the correlation coefficient between the variables are described in the relevant degree of strength, $|\mathrm{r}|$ is close to 1, shows that the higher level of two variables are related, also the result of the prediction is more accurate, so can choose the type of regression according to the principle of maximum.

\section{Back Propagation.}

BP network is three layers or more three layers above the hierarchical structure of the network, this paper USES the three layers BP neural network, consists of input layer, hidden layer and output layer. Assuming that BP network has $\mathrm{N}$ processing units on each floor, mode of training set contains $\mathrm{M}$ sample. In the first $\mathrm{p}$ a learning sample $(\mathrm{p}=1,2 \ldots \mathrm{M})$, the outputting is $O_{p j}$. If arbitrary set of initial weights, then for each input sample $\mathrm{p}$, its network output and the $\operatorname{expected}\left(d_{p j}\right)$ output error is

$$
E=\sum_{p} E_{p}=\left[\sum_{j}\left(d_{p j}-O_{p j}\right)^{2}\right] / 2 .
$$

Usually a weight correction formula needs to add inertial parameters of alpha, so there is the final formula of the back propagation:

$$
\mathrm{W}_{\mathrm{ji}}=\mathrm{W}_{\mathrm{ji}}(t)+\eta \delta_{\mathrm{pj}} O_{\mathrm{pj}}+\alpha\left(\mathrm{W}_{\mathrm{ji}}(t)-\mathrm{W}_{\mathrm{ji}}(t-1)\right) .
$$


Weight correction is done step by step in the process of error back propagation. Error correction by the output layer connection weights of each output layer unit to calculate the amount of error connected hidden layer units, and correct connection weights of hidden layer unit. So go on, the entire network weights updated once, namely after a learning cycle .After several learning cycle, when error of meet the requirements, the BP network learning. After the completion of the BP network learning can be related to predict.

\section{Case study}

According to the sample value first established GM $(1,1)$ model of railway passenger traffic and railway mileage to the regression model, the fitting values of the two models as the BP neural network input, with actual railway passenger traffic as ideal output to network training, setting accuracy is achieved when the error is to stop training, and then used to predict the trained network.

\section{Combination Forecast Process.}

The participants are the number of the people taking the train and the number of the operating distance. The arrangement of the number is from 2003 to 2011, like the table 1. Due to the database about the train operating and the GM $(1,1)$ model, we can get the result $a=-0.0651$, and $b=98231.55$, then the sequence of the time response should be

$$
\mathrm{x}_{(\mathrm{t}+1)}=1412503.7 \times \mathrm{e}^{0.07 t}-1315243.7 \text {. }
$$

Next step, we use the binary regression model and can establish the formulation:

$$
y=0.0325 x^{2}-0.0680 x+7.3952 \quad(x=1,2, \cdots) .
$$

Finally, we use the fitting model to compute the result. The mathematic soft used in the paper is the MATLAB.

The code in the MATLAB is showing as following:

$\mathrm{t}=[\mathrm{d} ; \mathrm{e} ; \mathrm{f}]$;

[pn,minp, maxp,tn,mint,maxt] $=$ premnmx $(\mathrm{p}, \mathrm{t})$;

$\mathrm{dx}=[-1,1 ;-1,1 ;-1,1 ;-1,1 ;-1,1 ;-1,1 ;-1,1 ;-1,1 ;-1,1] ; \%$

net $=$ newff( $\mathrm{dx},[9,12,3],\{$ 'tansig','tansig','tansig'\}, 'traingdx');

net.trainParam. show $=100$;

net.trainParam. $\mathrm{Lr}=0.1$;

net.trainParam.epochs $=10000$;

net.trainParam.goal $=0.0001$;

net $=$ train(net,pn,tn);

an $=\operatorname{sim}($ net,pn);

$\mathrm{a}=$ postmnmx (an,mint,maxt);

pnew $=[4 ; 4 ; 5 ; 4 ; 4 ; 4 ; 4 ; 4 ; 3]$;

pnewn=tramnmx (pnew,minp, $\operatorname{maxp}) ; \operatorname{anewn}=\operatorname{sim}($ net,pnewn);

anew=postmnmx (anewn,mint,maxt)

Tab.1 the Basic Number

\begin{tabular}{|c|c|c|c|c|c|c|c|c|c|}
\hline Years & 2003 & 2004 & 2005 & 2006 & 2007 & 2008 & 2009 & 2010 & 2011 \\
\hline $\begin{array}{c}\text { The } \\
\text { Number } \\
\text { of the } \\
\text { people }\end{array}$ & 97260 & 111764 & 115583 & 125655.8 & 135670 & 146192.85 & 152451.19 & 167609.02 & 186226.07 \\
\hline $\begin{array}{c}\text { Operating } \\
\text { distance }\end{array}$ & 7.3 & 7.44 & 7.54 & 7.71 & 7.8 & 7.97 & 8.55 & 9.12 & 9.32 \\
\hline
\end{tabular}




\section{The Fitting Result and Analysis.}

Use the established model and we can get the following result, shown as the table 2. In the table 3, we compute the average absolute error and the average relational error. We could find the fitting result is better than the signal result from analyzing the two kinds of error.

Tab.2 Fitting Result

\begin{tabular}{|c|c|c|c|c|c|c|}
\hline $\begin{array}{c}\text { Series } \\
\text { number }\end{array}$ & Years & $\begin{array}{c}\text { Passenger } \\
\text { Capacity }\end{array}$ & GM(1,1) & Operating Km & Polynomial & Predict \\
\hline 1 & 2003 & 97260.00 & 97260.00 & 7.30 & 7.37 & 97772.92 \\
\hline 2 & 2004 & 111764.00 & 109754.97 & 7.44 & 7.92 & 109995.25 \\
\hline 3 & 2005 & 115583.00 & 125459.30 & 7.54 & 7.47 & 117216.30 \\
\hline 4 & 2006 & 125655.80 & 146722.67 & 7.71 & 7.62 & 124689.30 \\
\hline 5 & 2007 & 135670.00 & 135374.15 & 7.80 & 7.77 & 137081.60 \\
\hline 6 & 2008 & 146192.85 & 145766.53 & 7.97 & 8.12 & 144310.19 \\
\hline 7 & 2009 & 152451.19 & 156956.72 & 8.55 & 8.57 & 153439.86 \\
\hline 8 & 2010 & 167609.02 & 169005.97 & 9.12 & 8.92 & 169099.52 \\
\hline 9 & 2011 & 186226.07 & 181980.20 & 9.32 & 9.47 & 184785.64 \\
\hline
\end{tabular}

Tab.3 the Fitting Result analysis

\begin{tabular}{|c|c|c|}
\hline Error & GM(1,1) & Predict \\
\hline Average Absolute Error & 1535.85 & 1343.92 \\
\hline Average Relative Error & 0.01 & 0.01 \\
\hline
\end{tabular}

\section{Result and analysis.}

Using the trained BP neural network prediction of railway passenger traffic from 2012 to 2016, as shown in table 4.From the perspective of the predicted in 2012, the actual passenger traffic and combined forecasting result is very close to the result of the combined forecasting is better than GM $(1,1)$ model to predict, the result of the prediction error analysis of the results as shown in table 5 .

From the perspective of the predicted in 2013-2016, the railway passenger traffic is still growing, but has a tendency to slow, and the relevant railway enterprises should analyze the causes, and take the necessary measures to maintain the continuous growth of the railway passenger traffic.

Tab.4 the Predict Results

\begin{tabular}{|c|c|c|c|}
\hline Years & Passenger Capacity & GM(1,1) & Predict \\
\hline 2012 & 189336.85 & 195950.44 & 199474.00 \\
\hline 2013 & - & 291093.15 & 179952.34 \\
\hline 2014 & - & 212790.66 & 280148.59 \\
\hline 2015 & & 234461.62 & 206210.90 \\
\hline 2016 & & 216341.48 & 206239.09 \\
\hline
\end{tabular}

Tab.5 Error Analysis

\begin{tabular}{|c|c|c|}
\hline Error & $\mathrm{GM}(1,1)$ & Predict \\
\hline Absolute Error & 6613.59 & 5457.15 \\
\hline Relative Error & 0.03 & 0.02 \\
\hline
\end{tabular}




\section{Conclusions}

Through analysis on fitting results and predicted results shows that based on GM $(1,1)$ model and regression model of BP neural network combination forecast model of railway passenger traffic forecasting is better than a single model. The combination forecast model is not only a BP neural network has the self-study habits, adaptability, and is a combination of GM $(1,1)$ model has the advantages of significantly reduced prediction error, better prediction effect. So the prediction results of the model can to provide the necessary decision support for the relevant railway enterprise.

\section{References}

[1] Lifeng Wu, Modeling GM(1,1) Based New Information Principle, Grey Systems and Intelligent Services, 2011.

[2] Junjie Kang, Huijuan Zhao, Application of Improved Grey Model in Long-term Load Forecasting of Power Engineering, Systems Engineering Procedia, 2012.

[3] Wiesel, A. Linear Regression With Gaussian Model Uncertainty: Algorithms and Bounds, Signal Processing, 2008.

[4] Li Zhang, Jianhua Luo, Suying Yang, Forecasting Box Office Revenue of Movies with BP Neural Network, Expert Systems with Applications, 36(2009), 6580-6587.

[5] Kisi O. Comparison of different ANN techniques in river flow prediction. Civil Engineering and Environmental Systems 2007:24(3):211-231.

[6] Bilgili M, Sahin B, Yasar A. Application of artificial neural networks for the wind speed prediction of target station using reference stations data. Renewable Energy 2007;32(14):2350e 60.

[7] Widrow B, Lehr MA. 30 years of adaptive neural networks: perceptron, Madaline, and back propagation. Proceedings of the IEEE 2002;78(9):1415e42.

[8] Kisi O. Comparison of different ANN techniques in river flow prediction. Civil Engineering and Environmental Systems 2007;24(3):211e 31.

[9] Wanas N, Auda G, Kamel MS, Karray F. On the optimal number of hidden nodes in a neural network. In: Proc. 1998 IEEE Canadian Conference on Electrical and Computer Engineering; 1998:918 e21. 